\title{
El 'homo religiosus' y su búsqueda de razones. La razonabilidad de la fe en la filosofía de Juan A. Estrada
}

'Homo religiosus' and the search for reasons. The reasonableness of faith in Juan A. Estrada's philosophy

José Antonio Pérez Tapias

Catedrático de Universidad, Departamento de Filosofía II, Universidad de Granada

\author{
ATEÍSMO, CREENCIA Y SENTIDO. HOMENAJE A JUAN ANTONIO ESTRADA \\ MONOGRÁFICO COORDINADO POR REMEDIOS ÁVILA Y MIGUEL MORENO
}

\begin{abstract}
RESUMEN
Las relaciones entre razón y fe atraviesan la historia de la filosofía. Con la secularización de la modernidad y el pensamiento crítico de la llustración, esas relaciones entran en una nueva fase: se cuestionan los dogmas y la filosofía también se plantea cómo recoger por la razón, desde su autonomía y límites, el legado de la religión. El filósofo Juan Antonio Estrada ha seguido la pista al hablar de Dios de la teología y a cómo incide el punto de vista de la redención en la filosofía. En la posmodernidad y su cultura nihilista la aportación de sentido de las tradiciones religiosas es herencia valiosa. El "Homo religiosus" busca las razones de su creencia. El profesor Estrada argumenta a favor de la razonabilidad de la religión, tratando de no caer en una "filosofía religiosa" que, desde Kant, no es aceptable.
\end{abstract}

\section{ABSTRACT}

The ways in which reason and faith are related have been extensively debated throughout the history of philosophy. The secularization of modernity and the emergence of critical thinking in the Age of Enlightenment, however, mark the starting point of a new phase: religious dogmas are questioned and philosophy attempts to pick up the legacy of religion using reason as a filter. The philosopher Juan Antonio Estrada has followed this line in his discourse about God in theology and the influence of redemption as a viewpoint in philosophical thought. In the era of postmodernism and nihilist culture, the sense and meaning provided by religious traditions is a valuable heritage. "Homo religious" strives for reasons for what they believe. Professor Estrada argues for the reasonableness of religion without falling into the trap of "religious philosophy", which is deemed unacceptable since Kant onwards.

PALABRAS CLAVE

filosofía | teología | religión | sentido | razón

KEYWORDS

philosophy | theology | religion | meaning | reason

\section{Al modo de Pascal: la fe tiene razones... El interés de la cuestión}

En lo que llamamos tradición occidental y en lo que en ella reconocemos como filosofía, esta no ha dejado de interactuar con la religión, sea dialogando con sus elaboraciones teológicas en busca de puntos de confluencia, sea para someterlas a crítica. La tarea hermenéutica respecto a las tradiciones religiosas ha tenido en cuenta, variando los acentos según contextos, las aportaciones de las religiones como tradiciones de sentido, su relación con la moral, su incidencia política, su articulación con los saberes en cada caso disponibles, su pervivencia a través de sus instituciones así como de sus prácticas rituales, etc.

La presencia en distintas épocas y sociedades de lo que se enuncia como "hecho religioso", siendo transversal a ellas gracias también a los cambios a los que se ve sometido para adaptarse a nuevas condiciones culturales, o debido a los mismos cambios que desde el ámbito religioso se propician, da pie a pensar que el homo sapiens es homo religiosus, afirmación que corroboran los estudios antropológicos y los registros arqueológicos, dejando para la indagación más actual cómo puede darse en nuestros días esa condición religiosa que atribuimos a sapiens. La historia, por lo demás, nos muestra cómo esa condición religiosa de los humanos, manifestándose de diversas maneras, ha estado sujeta, en especial en lo que entendemos como esa cultura occidental que ha ido gestándose hasta hoy desde hace más de dos milenios -reconstruyendo así genealógicamente ese proceso con mirada retrospectiva-, a transformaciones profundas que en algunos momentos se han condensado en hitos cruciales. 
Si entre los siglos I y IV se dio el proceso por el que el cristianismo se heleniza tras su ruptura originaria con el judaísmo del que procedía, a la vez que se adaptaba a las estructuras institucionales y cosmovisionales del Imperio Romano (perdió en ello buena parte de su inicial impulso profético), tras el período de cristiandad medieval y mediando la transición renacentista, la modernidad conllevó profundas transformaciones que afectaron sobre manera a la cultura en su conjunto y a la religión en su seno. Basta recordar lo que supuso el momento álgido de la Reforma luterana al poco de arrancar el siglo XVI, con la consabida reacción que supuso la Contrarreforma católica. Las estructuras sociales y económicas que se fueron imponiendo, con la burguesía como clase ascendente en esa etapa precapitalista, la nueva institucionalización de lo político en lo que acabarían siendo las monarquías absolutas en los nacientes Estados europeos, el surgimiento de la novedad epistémica de la ciencia experimental y las técnicas propiciadas por ella, los nuevos descubrimientos geográficos (América) y astronómicos (heliocentrismo) que modificaron sustancialmente la imagen del mundo y la autocomprensión de los humanos..., todo ello generó el marco en el que la religiosidad de la época se vio alterada y en el que la modernidad se confirmó también con un nuevo paradigma filosófico desde una reafirmada autonomía de la razón. Lo que denominamos proceso de secularización, que lo podemos definir para la época como emancipación de individuos y sociedades de la tutela de las instituciones religiosas, es clave para la inteligibilidad de la historia de la modernidad y, en su seno, de la misma evolución de las instituciones religiosas y sus modos de pensar y actuar, los cuales fueron respuestas a un contexto cultural en el que la religión tuvo que resituarse a medida que se vio desplazada de la vida pública y sometida a la vez a un escrutinio crítico progresivamente más acentuado (Gauchet 1985).

Así como los humanos modernos tuvieron que reconfigurar su identidad también en su condición religiosa, en el caso en el que la mantuvieran como tal si no pasaban al lado de las posiciones agnósticas, ateas o, simplemente, de indiferencia respecto a la religión, otro proceso de no menor envergadura es aquel en el que están inmersos los hombres y mujeres del momento histórico de finales del siglo XX y comienzos del XXI en el que la modernidad es apreciada en su crisis, en el que a la llamada postmodernidad le acompaña lo que para destacados pensadores es etapa postmetafísica -si no abiertamente antimetafísica-, y lo que para algunos es visto como fase postcristiana de nuestra cultura. No obstante, frente a una lectura de la modernidad en la que se veía en esta un proceso ascendente de secularización de la cultura, que era visto desde ciertas mentalidades "ilustradas" como llamado a desembocar, si no en la desaparición de la religión, sí en su irrelevancia cultural y en su inanidad social, resulta que al cabo los pronósticos en torno a los efectos y consecuencias del proceso de secularización se ven necesitados de revisión a fondo (Pérez Tapias 2019: 254 y ss.). El "hecho religioso" sigue mostrando una fuerte capacidad de resistencia a la vez que una gran versatilidad, aunque pueda decirse de las sociedades occidentales que en ellas la secularidad implicó "la no presencia de Dios en la vida pública" (Taylor 2007a: 17-18). Cuando surgen nuevos modos adoptados por las religiones tradicionales o cuando aparecen nuevas formas de religiosidad, incluso presencia de nuevas religiones, todo ello obliga a replantear las tesis en torno a la secularización, por más que ello no tenga que suponer adscribirse a las posiciones de teorías sociológicas rotuladas como postseculares. El caso es que la insatisfacción en cuanto a "respuestas de sentido" hace que no desaparezca la conciencia religiosa, si bien es cierto que se manifiesta de múltiples maneras en la actualidad, bajo nuevas formas de espiritualidad e incluso con nuevos modos de "creencia sin pertenencia" (Taylor 2007b: 257 y ss.).

En cualquier caso, si el abordaje crítico de la modernidad y su herencia obliga a la filosofía a considerar que pasó en ella con las religiones y su fe, especialmente en lo tocante a las relaciones entre fe y razón -cuestión que no deja de tener su correlato en cómo se han ido entendiendo las relaciones entre Iglesia y Estado, con el poder siempre por medio-, la situación actual del pensamiento filosófico, por una parte, y de las religiones -todo en su pluralidad-, por otra, hacen ineludible plantearse qué pasa con el homo religiosus en el contexto actual y qué tarea puede desempeñar la filosofía en torno a su realidad sociocultural y, especialmente, respecto a las convicciones de fe que siga albergando. Es respecto a esta cuestión que la obra filosófica de Juan Antonio Estrada mantiene a todo lo largo de su recorrido un interés primordial -podemos hablar de verdadero leit motiv- en esa relación entre filosofía y teología, razón y fe, que, desde el diálogo a partir de las diferencias -por lo demás, no ajenas al entrecruzamiento de herencias-, haga valer la razonabilidad de la fe, entendiendo que esta puede defenderse en lo que toca a convicciones de fe que se hayan dejado afectar por una razón crítica que las haya depurado de adherencias distorsionantes de los contenidos más genuinos de una fe religiosa madura -deteniéndose Estrada en los que son propios de la fe cristiana, sin que eso suponga por su parte afirmación de exclusividad para el cristianismo de dicha razonabilidad-. 
autonomía puede sostener? ¿Se puede seguir hablando de razones? ¿Por qué y cómo? Las cuestiones en torno a ello, si bien recuerdan la afirmación pascaliana de que "el corazón tiene razones que la razón no puede entender", no se pueden quedar en una declaración voluntarista que recaería en el fideísmo, ni pueden dar lugar a la salida consoladora de una "apuesta" en el vacío; son cuestiones que requieren confrontarse con distintas posiciones que, desde la crítica y a veces la propuesta, han abordado esta problemática de crucial calado. El profesor Estrada se ha dedicado amplia y fructíferamente a ello e invita a la tarea de poner en contexto sus posiciones al respecto para hacer un balance de las mismas. Estas se condensan en la afirmación con la que muestra su objetivo en su libro ¿Qué decimos cuando hablamos de Dios?: "mostrar que ser cristiano es razonable" (Estrada 2015: 15), en el bien entendido de que ese ser cristiano, que implica un modo de vida y una práctica religiosa, supone la asunción de un contenido de fe relativo al mismo Dios en su relación salvífica con el ser humano.

\section{La Ilustración ante la religión: recepción del legado racional de la fe y crítica del sacrificio dogmático de la razón}

La filosofía, desde su ya aludida tarea hermenéutico-crítica, no deja de atender a las tradiciones religiosas, las cuales son, entre otras cosas, tradiciones de sentido. Es una de las razones de su perdurabilidad, dada la misma función cultural que con ello cumplen, importante además para los humanos que viven en cada cultura -vinculadas siempre, en su origen remoto, a una matriz religiosa-. Todas se autocomprenden como portadoras de una verdad relativa al sentido de la existencia humana, individual y colectiva, sentido que, además de verbalizarse cuando las condiciones son adecuadas para ello, se vive en las prácticas rituales que, sin duda, son elemento indicador de la especificidad de lo religioso -algo subrayado por Jürgen Habermas (2012: 95 y ss.) al recogerlos de lo que aportan las ciencias de la religión, en especial la antropología cultural: el homo religiosus no puede dejar de ser homo ritualis-.

Sobre todo desde que en algunos contextos culturales se produjo hace milenios el salto cualitativo hacia las religiones universalistas de salvación -con ciertas distancias en el tiempo es lo que se produjo en lo que Jaspers denominó "era axial"- se intensificaron los procesos de racionalización de sus mensajes de sentido, siendo el momento en que aparecieron desarrollos intelectualmente más elaborados de su bagaje simbólico, gracias a determinadas circunstancias coadyuvantes -vinculadas a la sedentarización siguiente a la revolución neolítica: apoyatura política, organización sacerdotal, escritura, expansión cultural, etc.-, las cuales propiciaron que aparecieran teologías que, por su grado de racionalización, implicaban una desmitificación parcial de la propia herencia mítica.

La elaboración teológica, aun a riesgo de simplificar, podemos decir que siempre se movió entre dos extremos, recusables en cuanto precisamente extremos: una excesiva racionalización de la fe o un injustificable sacrificio dogmático de la razón. Lo primero se ha dado, rebasando a los mismos desarrollos teológicos, cuando ha habido condiciones propicias para dinámicas de ilustración y, en Occidente, cuando el proceso de secularización estaba más avanzado, aunque hay que señalar que tal exceso de racionalización puede absorber a la fe, neutralizando su especificidad, como también puede distorsionar a la razón al asumir contenidos de fe que no le corresponden. Lo segundo se ha producido en situaciones de repliegue cultural, de religiones a la defensiva que compensan con cerrazón intransigente, la cual ahoga los impulsos críticos en la misma racionalización teológica, reforzando las dinámicas fideístas y, por ende, irracionalistas.

La razón filosófica, en su legítimo juego del ir y venir combinando "voluntad de sospecha" y "voluntad de escucha", como dice Ricoeur, está obligada a esclarecer el antagonismo que representan las dos posiciones señaladas, abriendo entre ellos un espacio para una adecuada intelección de lo religioso, incluyendo una correcta interpretación de las teologías en curso. Clave para ello es que se lleve a cabo proceder a una desmitologización bien hecha, capaz de conservar el contenido de verdad de lo que en el lenguaje mítico, simbólicamente denso, se ofrece en relatos y rituales de una comunidad de fe, dando paso a elaboraciones teológicas no ajenas a criterios propios de una razón discursiva (Ricoeur 1960: 169 y ss.). La dificultad de esa necesaria desmitologización como clave para un ejercicio adecuado de explicación y comprensión de la realidad antropológica que late en la misma experiencia religiosa, sin prescindir de su dimensión intelectual, la podemos verificar en tres planteamientos que muestran de forma paradigmática distintas posturas respecto a la religión y a la teología en el marco de la llustración europea. Hablemos de las posiciones de Kant, de Hegel y de Feuerbach al respecto. 
Siendo el de Kant un primer planteamiento a subrayar, por lo que supone de madurez del espíritu de la llustración y de un enfoque acerca de la religión y de los contenidos teológicos que nos lleva a un nivel de reflexión y argumentación más complejo que el de ilustrados anteriores, como es el caso de Voltaire y otros deístas o de los mimos autores que, sobre todo en Francia, fueron exponentes de un materialismo ateo, hay que poner de relieve dos aspectos correlacionados de su pensamiento: a la vez que el teísmo filosófico, resultante de una teología filosófica sostenida como piedra angular de la metafísica, era descartado como racionalmente asumible, se inicia un tratamiento de la religión en general que se puede considerar como punto de arranque de la filosofía de la religión, sobre todo tal como la cuestión queda expuesta en La religión dentro de los límites de la mera razón.

Como sabemos, Kant presentó un novedoso planteamiento filosófico en el que se combinaban agnosticismo teórico y teísmo práctico ("teísmo moral"; véase Gómez Caffarena 1983). Su agnosticismo, que no llega a ser metafísica atea por el papel de Dios como idea regulativa -no manejable categorialmente y con una existencia postulada desde la razón práctica-, responde a una razón filosófica consciente de sus límites y consecuente con su finitud, pero que a la vez exige a la teología estar a la altura de su propio criticismo, como corresponde a la elaboración teológica de una "religión dentro de los límites de la razón". El sofisticado teísmo práctico kantiano retoma el discurso teológico desde la razón moral, dándose ahí una racionalización de lo teológico que llega desde la razón práctica a donde se prohibió acceder la razón teórica al dejar a Dios, desde el trascendentalismo propio de la crítica kantiana, solo como "idea regulativa de la razón". Con el valor de la autoconsciencia de una razón finita, esta, aun siendo consciente de su alcance desde su autonomía, comporta la limitación del sapere aude que se autorrefrena ante ciertos contenidos teológicos. Y ello es así aunque está acompañado por el paso de Kant hacia el carácter crítico que propugna para la misma razón teológica, como bien se puede apreciar en su defensa del "uso público" de la razón incluso desde el campo teológico en relación a la misma teología: el teólogo "tiene plena libertad, e incluso la vocación, para comunicar al público todos sus pensamientos, cuidadosamente examinados y bienintencionados, sobre los defectos de tal símbolo (de la iglesia a la que sirve) y las propuestas para mejorar la institución de la esencia de la religión y de la iglesia" (Kant 1784: 67). Su posición al respecto es, pues, un hito que desde el lado de la teología no se debería perder de vista.

La segunda propuesta aludida es la representada por la filosofía especulativa de Hegel. El autor de la Fenomenología del Espíritu elevó el listón de las pretensiones de la razón filosófica, partiendo de la crítica, no de los logros, pero sí de las que estimaba insuficiencias del trascendentalismo kantiano por lo que a su parecer comportaba de dualismos y lastre de "conciencia desgraciada". El saber de la totalidad, articulado como sistema que habría de dar cuenta del devenir del Espíritu Absoluto a lo largo de esa historia en la que se aliena para recuperarse plenamente a sí, en la reconciliación final de las contradicciones a las que la densidad de lo negativo somete el curso histórico, es explícito sobrepujamiento de una razón que lleva a extremo la racionalización de la fe pretendiendo dar cuenta de su contenido mediante un saber especulativo al que la teología, atada a la positividad de la religión, no puede llegar: "Dios solo es asequible en el puro saber especulativo, y solo es en él y solo es este saber mismo, pues es el espíritu; y este saber especulativo es el saber de la religión revelada" (Hegel 1807: 441). Es lo que Hegel (1848: 52) siempre reafirmará: "La filosofía tiene que hacerse cargo del contenido de la religión, incluso contra algunas formas de teología". En este caso, el exceso especulativo hegeliano, olvidando los límites de la razón, distorsiona la diferencia entre lenguaje conceptual y lenguaje simbólico, fundamental para una adecuada hermenéutica de lo religioso y un correcto planteamiento metafísico de lo relativo al sentido.

Una tercera propuesta que nos interesa destacar es la representada por Feuerbach y su reducción antropológica de la teología. En La esencia del cristianismo, arrancando en su caso de la crítica a Hegel por la criptoteología que permaneció bajo el ropaje del saber especulativo, y queriendo llevar hasta el final lo que la ambigüedad hegeliana no se atrevió a resolver (partiendo, por ejemplo, de la afirmación de que "la naturaleza divina es lo mismo que lo que es la humana y es esta unidad lo que deviene intuida" (véase Hegel 1848: 440), Feuerbach lleva adelante, con su método genético-crítico, la consumación de la crítica filosófica de la religión y de la teología. Mas lo hace queriendo rescatar la "verdad de la teología", que es la antropología. Este es su secreto: lo que el discurso teológico dice del hombre (que lo formula) cuando habla del Dios (al que se refiere). Desvelada la antropología como el "misterio de la teología" (Feuerbach 1841: 32) no queda más que la afirmación del ateísmo humanista como vía de salida de la enajenación religiosa. El uso crítico de la razón, más allá del comedimiento kantiano y del exceso hegeliano, no se opone a una consideración de la religión como manifestación humana sumamente valiosa -y en alguna forma, imprescindible-, pero sí a la consideración de una razón teológica como 
miembro de pleno derecho entre los diferentes campos de la racionalidad humana.

Con tan sucintas alusiones a tres autores representativos de una llustración que atiende a lo religioso, alejándose de tratarlo sin más como ámbito donde solo reinan la superstición y falsas ilusiones, se puede entender fácilmente la sintonía del filósofo Estrada con el modo kantiano de abordar la religión y de mantener el teísmo como opción racional. Si cabe decir que es irrebatible la crítica kantiana a la teología filosófica tradicional o a la misma metafísica moderna previa a ella, en tanto que seguía siendo onto-teológica, incluso como metafísica de la subjetividad, puede subrayarse además con énfasis cómo, tras una crítica que deja como indefendible la teodicea especulativa al modo de Leibniz, se abre camino un teísmo moral que afirma la existencia de Dios como postulado de la razón práctica, poniendo a Dios en el horizonte último de un "bien supremo" en el que pueden converger virtud -la que implica actuar por deber en la existencia del sujeto moral- y felicidad, como fuente de sentido de la vida moral, sin merma de las exigencias de la autonomía de la razón y sin falsos consuelos ante la irresoluble problemática del mal. El giro kantiano es fundamental para "superar la teodicea tradicional", contribuyendo así a replantear la misma imagen de Dios (Estrada 1977: 348). De suyo, con el postulado de Dios -pensado, pero no conocido-, se afirma su existencia como -dice Estrada 2003: 277, apuntando más lejos- "exigencia racional de una conciencia moral" (Estrada 2003: 277), de forma tal que con ella Kant da muerte al "dios de los filósofos" para "dejar abierto un espacio al Dios de las religiones, al Dios de la revelación" (Estrada 2003: 300 y ss.).

Puesto a situarse en la órbita de Kant, el profesor Estrada lo matiza diciendo que a estas alturas de la historia lo que procede en tal sentido es un "kantismo poshegeliano". Reconociendo los méritos de Hegel por hacerse cargo en su idealismo especulativo del contenido racional de la religión -del cristianismo en verdad-, su pretensión de amortizarla, considerándola como cauce de expresión simbólica en la vida de los individuos en el seno de su comunidad de aquello que la filosofía vendría a expresar plenamente en el concepto, es algo que no se puede aceptar por la misma desmesura de una razón que afirma tan enfáticamente su autonomía que, en su magna restauración de la metafísica de la mano de una razón histórica, se olvida de su finitud. Considerar la filosofía como portavoz del Espíritu Absoluto en la historia, haciéndole jugar el papel de una nueva teodicea en versión de historiodicea, viene a ser para Estrada (2003: 125) caso paradigmático de una secularización de la religión y sus contenidos en la que la filosofía retiene para sí connotaciones teológicas de la religión que se dice superar -en el riguroso sentido de Aufhebung-.

La desmesura hegeliana tratando de llevar a la filosofía allí donde piensa que la razón humana puede acceder comporta una "criptoteología metafísica que se presenta de forma secularizada", lo cual dará pie a su crisis posterior, empezando por el cuestionamiento al que somete Feuerbach al sistema de Hegel en tanto lo ve, y no le falta razón, cargado de teología, lo que obligará posteriormente una y otra vez a señalar "posibilidades y límites de la razón" (Estrada 2003: 266). Por ello, si Marx, Nietzsche y Freud son considerados como "maestros de la sospecha" -siguiendo la exitosa caracterización de Ricoeur- por poner en cuestión la conciencia misma y no solo lo que ella "produce", Estrada añade a ellos en muchos momentos el nombre del autor de La esencia del cristianismo, obra que sin duda abrió el camino a los tres siguientes para la crítica de la religión y para la crítica de las ideologías (Marx), la crítica de la cultura (Nietzsche) o la crítica de las racionalizaciones del inconsciente (Freud). Los tres, por su parte, reconocieron, cada cual a su modo, una vertiente de la religión que se retiene tras la crítica a sus efectos alienantes sobre los humanos: la religión como "grito de la criatura oprimida" en Marx, la religión como "neurosis colectiva" que libra de mayores recaídas en neurosis individuales en el Freud de El malestar en la cultura, o la religión, una vez hecha la crítica a su vinculación a la "moral de esclavos" que alimenta el nihilismo negativo por Nietzsche, vista como ámbito en el que quepa plantear "cómo es posible la fe en Dios en una cultura postcristiana", punto que pone de relieve Estrada (2001: 204), si bien dejando pendiente de qué Dios se puede hablar en términos postnietzcheanos. Después de todo, el filósofo de la "muerte de Dios", diagnosticando su eliminación de nuestra cultura por vía de avance de un nihilismo que lo "mata" con más empeño que el ateísmo, no deja a su vez de ser -escribe Estrada 2003: 125- "el denunciador de la secularización europea con su afirmación de que las sombras de Dios son alargadas"; es decir, subsisten referencias que remiten a la religión y la teología aunque hayamos olvidado sus raíces originarias.

Una obligada estación hay que hacer en el pensamiento de Kierkegaard. No está de más tener en cuenta al pensador danés precisamente para perfilar la posición de Estrada respecto a la fe y respecto al estatus de la religión como merecedora de interacción con la filosofía (Estrada 1997: 349). Recordemos de camino que Kierkegaard, junto con Schleiermacher, es quien el mismo Habermas destaca como 
exigiendo a la filosofía que aceptase a la religión como interlocutora a su altura, y no meramente como algo del pasado, por más que dejara una herencia valiosa (Habermas 2005: 247 y ss.). Estando de acuerdo en gran medida con Feuerbach en su crítica a Hegel, aunque por distintos motivos, y acentuando frente a este la dialéctica de la interioridad frente a la dialéctica del Espíritu Absoluto a lo largo de la historia, Kierkegaard se opone radicalmente a toda racionalización de la fe que amortice la singularidad de su contenido. Tampoco está por sacrificar sin más a la razón en el altar del dogma, al modo de una fe antiilustrada. Su posición, así, también le distancia del teísmo moral kantiano por lo que pudiera tener de reducción de la religión a moral en una suerte de racionalización mitigada, con lo cual redunda en una neta separación entre la fe y la razón. Si la razón, y la filosofía con ella, no pasa de la angustia y la desesperación para tomarse la existencia en serio, solo el "salto de la fe", llevando al hombre a su estadio religioso, puede proporcionar el encuentro con una verdad de sentido que solo la fe del individuo ante Dios puede experimentar. Es el "coraje de la fe", acompañado de la humildad y no de la insolencia (de la especulación pretenciosa), el que permite encontrar su sentido a un yo no soluble en la dinámica de la especie (Kierkegaard 1849: 128). Sin embargo, descontadas las razones que se pueden compartir con el filósofo danés, obligado es reconocer que, incluso llevando al extremo el antagonismo entre ética y fe -contra Kant-, asume una versión maximalista de fideísmo que deja atrás las referencias agustinianas al absurdo de la fe para encumbrar a un Abraham, visto como irracionalmente obediente, porque "creyó en virtud del absurdo" (Kierkegaard 1843: 28). Por un camino así, aunque se rete a la razón filosófica, no se apunta a una vía que sea transitable para esta más allá del pertinente cuestionamiento a sus excesos especulativos o totalizantes. Es por ello que Estrada, reconociendo que con la resurrección en cuanto contenido de la fe cristiana se abre otra dimensión de sentido que Kierkegaard subraya con fuerza (Estrada 2010: 235), piensa que no por eso el teísmo cristiano ha de quedar al margen de lo que "desde una perspectiva racional" puede contemplarse en cuanto a su plausibilidad y credibilidad (Estrada 2005: 381).

\section{De la Teoría Crítica al pensamiento postmetafísico: la filosofía, desde la razón, se toma en serio la religión}

Kant y Hegel, desde planteamientos distintos, trataban de hacerse cargo de lo que suponía la religión y el discurso que desde ella se elaboraba como teología. Lo hicieron aplicando enfoques críticos -desenfocados, según Kierkegaard- que luego Feuerbach radicaliza en clave de ateísmo humanista, pero tratando de "conservar" la herencia de la religión, es decir, el secreto antropológico de la teología. En la órbita de esa actitud que, aunque crítica sin concesiones, parte de que en la religión hay un núcleo de verdad, aunque sea "invertido" -como diría Marx-, que hay que rescatar y hacer fructificar en terreno laico, está la que encontramos en otros autores que también se han confrontado con lo que supone lo que llamamos antropológicamente el "hecho religioso" -persistente, como dijimos, a pesar del secularismo en tanto dinámica sociocultural, que es constatación en la que Estrada viene a coincidir con Habermas a la hora de pensar la religión en las sociedades contemporáneas (Estrada 2004: 21 y 2006 : 103 y ss.).

Especialmente próximo a Feuerbach, pero inscribiéndose de lleno en la tradición marxista, se sitúa Ernst Bloch. En él puede hablarse de la herencia de la religión en el marco del "trascender sin trascendencia" que teoriza a partir de su ontología procesual. El autor de El principio esperanza considera la religión, en su vector humanista y profético, como cauce por el que se han expresado, en clave de esperanza de salvación, anhelos humanos de justicia y liberación que son los que encuentran plasmación en las distintas manifestaciones de la razón utópica y los que aguardan a ser realizados "materialistamente" en clave de emancipación (Bloch 1959: 400-408). En tanto que la religión y la teología también han cosido sus mejores vivencias y textos con "hilo rojo", para Bloch (especialmente 1968) son más que respetables interlocutoras que no han de faltar en el diálogo de la filosofía. Por todo ello, un pensamiento tejido con esos mimbres merece por parte de Estrada toda su consideración, no solo por la articulación de su ontología, sino por el aliento que insufla a la praxis transformadora de la realidad social desde su filosofía de la esperanza y con el compromiso que entraña su humanismo ateo. Con todo, nuestro autor, en La imposible teodicea, no pasa por alto lo que para él es objeción fuerte al "optimismo militante" blochiano en torno a la procesualidad histórica. Lo enuncia así: "El precio a pagar, sin embargo, es el del individuo, que se sacrifica por una humanidad que no conoce y de la que participa solo intencionalmente" (Estrada 1997: 328). Esto es, a pesar del impulso de una esperanza racional, el sentido de las vidas de los individuos -el punto fuerte de Kierkegaard- queda en el aire incluso con la hipótesis utópica de la superación de las negatividades históricas, puestas estas, contando con logros a ese respecto, a 
incontables humanos no les llegan en el transcurso de sus vidas, y menos si les son arrebatadas como víctimas en lo que el mismísimo Hegel llamó "el matadero de la historia". El ateísmo, subraya Estrada, enmudece ante el Holocausto (Estrada 2001: 167). Y en cualquier caso queda -dicho con fórmula paulina- la muerte como "último enemigo".

Es esa gran objeción frente al muy valorado Bloch lo que nos sitúa en la pista de la vecindad en la que se instala Estrada respecto a la Teoría Crítica. Precisamente en cuanto a tomarse en serio la teología es Horkheimer -a quien nuestro autor dedicó su tesis doctoral en Filosofía (1990)- uno de los filósofos contemporáneos que desde posiciones ateas más lejos ha llegado. Por algo Habermas, en "Creer y saber", recoge esa frase suya en la que, refiriéndose con paradójica ironía a la Teoría Crítica, dice que esta "sabe que Dios no existe, pero cree en él" (Habermas 2001b: 143). Ya sin ironía, posición análoga la encontramos en Adorno cuando, por ejemplo, en el último de sus aforismos en Minima moralia (1951: 251, parágrafo 153) escribe lo siguiente: "El único modo que aún le queda a la filosofía de responsabilizarse a la vista de la desesperación es intentar ver las cosas tal como aparecen desde el punto de vista de la redención. El conocimiento no tiene otra luz iluminadora del mundo que la que arroja la idea de la redención: todo lo demás se agota en reconstrucciones y se reduce a mera técnica. Es preciso fijar perspectivas en las que el mundo aparezca trastrocado, enajenado, mostrando sus grietas y desgarros, menesteroso y deforme en el grado en que aparece bajo la luz mesiánica".

Es fácil entrever los motivos de la sintonía de Estrada con los filósofos de aquella primera generación de la Escuela de Frankfurt. Un planteamiento filosófico desde una razón crítica y autocrítica, con matriz dialéctica, reformulando el materialismo histórico de Marx contando con las aportaciones de Freud y de Weber, entre otros, con una tensión crítico-utópica de la que no se desprende a pesar de la terrible experiencia sufrida bajo el nazismo... y que con todo ese bagaje considere que no se puede prescindir del "punto de vista de la redención", aunque no se pueda disponer de él, es una filosofía que para nada vuelve la vista hacia planteamiento teodiceico alguno, pero escucha a la tradición religioso-teológica -judeocristiana en este caso- porque lleva el aguijón de la "añoranza de lo absolutamente otro" reconocida por Horkheimer. Es a esa añoranza a la que Horkheimer (2000: 194-195) añade, como un grito de resistencia, que "la injusticia no puede ser la última palabra". Pero siendo el caso que la filosofía no la puede pronunciar, Estrada (2015: 159) se hace eco de la desgarrada fórmula de Horkheimer para recordar que precisamente la fe religiosa, esa para la que él pretende razonabilidad, "responde al problema del sentido de la vida, marcado por la injusticia y la muerte". Es el aguijón que percibimos clavado una y otra vez en la piel de la razón cada vez que la memoria nos trae el recuerdo de lo que no debe ser olvidado, lo que reclama la redención de la cual la filosofía no puede hablar: la muerte de las víctimas injustamente masacradas. Eso es lo que Benjamin puso sobre la mesa del debate filosófico y del diálogo de la filosofía con la teología.

En el humano anhelo de felicidad late un ansia no satisfecha de justicia y son esos dos polos del deseo humano los que cubre la promesa salvífica de redención. Redención es rescate, rescate del olvido, del sufrimiento padecido, de las injusticias soportadas, de la muerte acaecida... Y nada de eso puede asegurar la filosofía. Como se puede decir desde J.-B. Metz, ese gran teólogo que se dejó impactar por la memoria de las víctimas, ese es el "aguijón apocalíptico" que con su dolor revela de continuo una esperanza pendiente que escapa a la razón (Pérez Tapias 1999). Metz tenía presente a Walter Benjamin y la segunda de sus "Tesis de filosofía de la historia": "En la representación de la felicidad vibra inalienablemente la de redención. Y lo mismo ocurre con la representación del pasado, del cual hace la historia asunto suyo. El pasado lleva consigo un índice temporal mediante el cual queda remitido a la redención. Existe una cita secreta entre las generaciones que fueron y la nuestra. Y como a cada generación que vivió antes que nosotros, nos ha sido dada una flaca fuerza mesiánica sobre la que el pasado exige derechos. No se debe despachar esta exigencia a la ligera. Algo sabe de ello el materialismo histórico" (Benjamin 1940: 178). Estrada, por su parte, cuya simpatía por Metz es explícita, recoge una y otra vez el reto benjaminiano de la memoria por las víctimas, lanzado a la filosofía y que por otro lado obliga a la teología a afianzarse con más fuerza en la memoria del Crucificado como recuerdo revelador que en el simbolismo de la resurrección encuentra la expresión de su promesa de salvación. Pero si para la teología, como decía Metz, la resurrección sin la crucifixión -condensación de toda la injusticia, sufrimiento y muerte de este mundo- es un mito, para la filosofía, en lo que le toca, la memoria de las víctimas es definitivo alegato contra toda teodicea, para insistir desde ahí en que sí se postula la existencia de ese Dios cuya revelación pasa por la memoria de dichas víctimas (Estrada 2005: 411).

Si del punto de vista de la redención, por tanto, debe hacerse cargo la filosofía, pero sin que pueda disponer de él, de ninguna manera se debe volver a caer en alguna variante del error de Hegel: sacrificar 
la dimensión redentora del futuro salvífico del que habla la fe a un racionalizado devenir con desembocadura en una insostenible "patria de la identidad" o realidad intrahistórica de reconciliación total y definitiva. No vale ninguna bienintencionada propuesta de realizar en el seno de la historia todo lo que la perspectiva soteriológica situaba en la trascendencia y luego se trajo, mediando exceso secularista, al plano de la inmanencia (Voegelin 2000).

La crítica de los idealismos teológicos deja de ser crítica cuando éstos se amortizan como infundados utopismos intrahistóricos (Pérez Tapias 2007: 339 y ss.). Por tal razón, Habermas, con buen criterio, insiste en la necesidad de que la "razón profana" tenga en cuenta lo que transmite la religión y elabora discursivamente la teología, pero manteniendo las distancias, sin "con-fusiones", lo cual es además necesario para que también se "traduzcan" los contenidos morales y emancipadores de las tradiciones religiosas, susceptibles de ser compartidos más allá de sus entornos comunitarios, al lenguaje de una cultura secularizada (Habermas 2001b: 141-144). Estrada, que mantiene alguna distancia respecto a la propuesta habermasiana de "traducción" del lenguaje religioso al lenguaje secular, por el riesgo de que eso suponga una reducción de los contenidos de la fe a lo que el discurso filosófico y el lenguaje político dominante pueda digerir (Estrada 2004: 218 y ss.), señala igualmente cómo una mal hecha secularización del escatologismo judeocristiano ha dado lugar a desarrollos utópicos concluyentes en distopías (Estrada 2001: 167 y ss.).

Habermas, con el que Estrada (2004) confronta sus argumentos de manera singular, sobre todo a partir de la ética del discurso como ética ciertamente "sin teología", tras reconocer sin complejos el parentesco histórico y temático de la filosofía con la teología y subrayando la necesidad de mantener una clara diferencia metodológica entre sus respectivos discursos -se deben a distintos usos de la razón-, insiste en que "una filosofía que traspasa la barrera del ateísmo metodológico pierde la seriedad filosófica" (Habermas 2001a: 202). Se trata de un punto de vista que viene a coincidir con el sostenido con especial énfasis por el pensador judeo-francés Emmanuel Lévinas (1961: 66-102 y 308) cuando defiende con nitidez encomiable una metafísica "a-tea". Si bien en algún pasaje de sus escritos Estrada (1997: 357) hace referencia a que "la tematización de la ética como filosofía primera -clara alusión a Lévinas- tiene base en la tradición profética y jesuana", su atención se ha volcado más sobre la ética de Habermas, que este mismo presenta abiertamente como propia de un pensamiento postmetafísico, el cual se reconoce heredero de una metafísica que no puede ya mantener -planteamiento que por cierto no deja de ser análogo respecto al que guarda hacia la teología, analogía con apoyatura en el hecho de que la misma metafísica moderna vino a defender una teología filosófica, cuando no teodicea-, mas de manera tal que eso no le arredra a la hora de proponer una ética comunicativa desde el paradigma intersubjetivo del lenguaje que reemplaza al paradigma metafísico de la conciencia (solipsista).

El planteamiento de Habermas propone, pues, una ética que enfoca toda su fuerza argumentativa al servicio de la obligatoriedad de las normas morales -más su correlato político de normas legales en el espacio público democrático-, según un imperativo reformulado en términos de búsqueda del acuerdo entre los que se dan la norma, pero tratándose a todas luces de una ética sin un Fundamento -no se desentiende del intento de justificación racional desde una "pragmática universal"-, algo ya excluido tras las críticas al respecto de Nietzsche y Heidegger. Lo destacable ahora, desde la lectura que hace Estrada de Habermas, son los dos siguientes puntos.

En primer lugar, que Habermas presente su pensamiento como postmetafísico -nunca antimetafísico- no significa que se haya librado de la metafísica, punto que Estrada argumenta tomando como base que la metafísica no se puede eludir, y menos cuando se pretenden conclusiones éticas con fuerza normativa de deber moral. Si el pensamiento postmetafísico implica renuncia a toda metafísica -no se contempla la alternativa del nuevo paradigma metafísico que puso en juego Lévinas-, entonces acaba situándose al lado de formas expresas de pensamiento posmoderno que, por vía de deconstrucción u otras, terminan inermes frente al nihilismo, el cual, más allá de sus versiones estrictamente filosóficas, inunda culturalmente nuestras sociedades (Habermas 2001a: 167 y ss.). En el fondo, Estrada (2005: 380) piensa que el ser humano, por las cuestiones que ineludiblemente ha de afrontar aunque no pueda darles -darse a sí mismo- respuestas concluyentes, es un "animal metafísico", de la misma manera que el Sapiens es Homo religiosus, aunque no lleva de la mejor manera posible su religiosidad, sino muchas veces, como la historia ha mostrado y los críticos de la religión han enfrentado, cual "patologías religiosas" incrustadas en las mismas prácticas culturales (Estrada 2005: 313 y ss.).

Y en segundo lugar, el hecho de que Habermas aborde la religión y la teología con la máxima seriedad, con un diálogo fluido con representantes destacados de la mejor teología contemporánea -bien es 
verdad que casi reducidos en su nómina a alemanes-, no quita para que Estrada piense y diga que su misma ética del discurso queda un tanto impermeable a motivos que de cara a la ética pone en juego la fe religiosa, mostrando una reticencia que no desaparece a reconocer las razones, reconocibles como tales por el lado de la filosofía, que desde la religión y la fe que implica se pueden hacer valer. Estrada (2001: 195) piensa que se hacen valer de hecho, puesto que "el hombre religioso apuesta desde una razón que no tiene por qué ser ilusoria". Si es correcto pensar que la razón de una ética autónoma "ha de estar abierta al espacio religioso del que no puede prescindir" (Estrada 2004: 219), y Habermas cumple con ello, lo que viene a pensar nuestro autor es que tal cosa ha de hacerse con una apertura, sin reduccionismos en ningún sentido, desde la confianza en su valor y necesidad.

Es llamativo que en las mismas páginas de Por una ética sin teología, nuestro filósofo de Granada recoja una muy interesante cita del Horkheimer de la Crítica de la razón instrumental en a que este afirmaba que "la muerte de la razón especulativa, primera servidora de la religión y luego su contrincante, puede resultar funesta para la religión misma" (Estrada 2004: 223, nota 40). Es decir, con el vínculo que subyace a ellas, la religión pierde sin una metafísica al lado -con la que dialogar sin confundirse-, pero ese es un diagnóstico que tiene como correlato que la metafísica -incluso la oculta en el pensamiento postmetafísico, aunque sea algo que Habermas rechazaría reconocer- sin religión al lado, esto es, la filosofía sin religión al lado, igualmente puede padecer de forma grave la carencia de tal vecindad. En definitiva, para Estrada (2005: 380), si "no hay teísmo ni religión sin presupuestos metafísicos" -entendiendo bajo tal fórmula "metafísica" en un sentido amplio que va más allá de las elaboraciones de la metafísica en el ámbito académico, algo así como la "filosofía mundana" de Kant-, también puede decirse mutatis mutandis que no hay metafísica -entiende Estrada que sin metafísica la filosofía pierde su elemento nuclear- si el pensamiento filosófico no se hace cargo de lo que la religión y sus símbolos le "dan que pensar", cuestión que afirma con esa conocida fórmula ricoeuriana de Finitud y culpabilidad (Estrada 1997: 399).

\section{Sin necesidad de una "filosofía religiosa", el Homo religiosus puede apostar por la razonabilidad de la fe}

Juan Antonio Estrada, tras una larga trayectoria en la que se ha ocupado filosóficamente de las religiones y de Dios (sería imperdonable dejar de mencionar sus dos volúmenes sobre Dios en las tradiciones filosófica, 1994 y 1996), señala a lo largo de ella (y es algo que se aprecia sobre todo con su seguimiento del pensamiento ilustrado y de lo que piensan filósofos contemporáneos al respecto y de forma preeminente en su lectura receptiva y crítica a la vez de Habermas) los argumentos que se pueden ir hilvanando para defender las razones de la fe religiosa, como razones distintas de las que el discurso de la racionalidad propia de la filosofía o de las ciencias hacen valer desde su especificidad y autonomía. Estrada no solo se pone al lado del Homo religiosus de hoy en la búsqueda de razones de una fe que busca entender -dicho recordando a Agustín de Hipona-, sino que él mismo es un hombre religioso en el que concurre la condición de filósofo. La ineludible e insuperable tensión entre religión y filosofía (Estrada 2003: 308-309), aun afirmando que se necesitan, la lleva consigo, y eso le obliga a mantenerla sin anularla.

El punto de partida antropológico que de continuo está presente en la reflexión de Estrada es la necesidad humana de sentido, haciéndose presente una y otra vez en la búsqueda de respuestas al por qué y al para qué de la existencia y a la pregunta sobre el valor de dicha existencia frente a las realidades que la cuestionan: injusticia, sufrimiento, muerte. Tal telón de fondo antropológico es el que se hace indispensable para sostener convicciones éticas respecto a cómo debemos actuar en nuestras relaciones humanas -incluido cada cual consigo mismo- y desde dónde sostenemos como incondicional el respeto que nos debemos a todos y cada uno de nosotros: lo que llamamos dignidad. Es frente al sinsentido, que en una cultura como la nuestra, epocalmente marcada por un acentuado nihilismo que incluso deja atrás el escepticismo de etapas anteriores, que la religión y la filosofía asumen la tarea de articular respuestas. Si la filosofía, desde la finitud de la razón, llega hasta un punto en el que no le queda sino callar a falta incluso de categorías adecuadas para cuestión tan grave como crucial, reconociendo que cualquier teodicea -justificación del mal desde un Dios filosóficamente pensado- es un camino impracticable, la religión se mantiene como fuente de sentido cuyo caudal recoge la fe del creyente. Estrada defiende al respecto que la religión aporta no solo una apoyatura desde los afectos -máxime en el consuelo que puede brindar una comunidad que en sus rituales celebra los misterios de su fe-, sino unas razones de inteligibilidad en torno a la vivencia de un sentido que, sin embargo, no por 
eso facultan a la teología que las elabora intelectualmente el camino de una teodicea concluyente. Una religión no ajena a una racionalidad crítica, y eso es para Estrada condición de una religiosidad madura, ante la pregunta de si podemos asumir un cristianismo sin teodicea -puesta esta religión en el punto de mira-, la respuesta es sí; es más, no queda otra, puesto que "el cristianismo no ofrece una teodicea" (Estrada 2010: 235-238). También para la teología, en tanto elaboración de la razón sobre los contenidos de la fe, el mal es "problema irresuelto" (Estrada 2015: 159). Se puede decir que el "silencio de Dios" es clamoroso.

Asumido, pues, que la teodicea es imposible, Estrada (1997: 399) insiste en ello a la vez que trata de mostrar la vía por la que la conciencia religiosa (cristiana en este caso) puede mirar más allá del sinsentido: "No hay justificación racional del mal, pero sí de la validez racional de la fe y del compromiso esperanzado que genera". En el caso del cristianismo, la esperanza del sentido que entraña, no remitiéndose a argumentos de un discurso racional concluyente, sí lo hace en torno a la experiencia de muerte y resurrección del Crucificado vivida como revelación privilegiada de Dios en esa suerte de figura "de un mesías antimesiánico" en la que se concentra simbólicamente el dolor del mundo que aspira a redención. En este caso, la respuesta religiosa a la cuestión del sentido es respuesta desde la "locura" de resurrección y justicia final, desde la cual -añade Estrada- también es posible considerar que "el cristianismo tenga razón y apunte a una verdad última del hombre" (Estrada 1997: 399). Sería respuesta "para tantos Jobs que han muerto sin consolación" (Estrada 1997: 349).

Con tales planteamientos cualquiera podría pensar que el filósofo Estrada se deja ir hacia una tarea apologética, cediendo ante su vertiente teológica para ir más allá de lo que la filosofía puede hacer en relación a un sentido cuyo solo esbozo discursivo se nos convierte poco menos que en tarea inalcanzable para una razón autónoma pero anclada en la finitud. No obstante, a decir verdad el filósofo Estrada, como Jacob luchando contra Yahvéh en el relato bíblico, batalla con el mismo lenguaje, con sus propias formulaciones, señalando a donde la filosofía no llega, pero no puede dejar de tener en cuenta al modo adorniano. Es cierto que "no necesitamos el recurso a Dios para fundar la moral" (Estrada 2005: 410), como afirma y hace Habermas, entre otros. Pero eso no es óbice para pensar como "razonable defender un sistema de creencias, una forma religiosa de vida" como algo racional y coherente (Estrada 2005: 408). De todas formas, defendiendo así la razonabilidad del cristianismo -extensible a otras religiones-, nuestro autor se encarga de poner sobre aviso acerca de la impertinencia de reducir lo religioso a su legado moral -al modo, por ejemplo, que ya hizo Durkheim al valorar la religión por su aportación a la socialización moral y a la cohesión de la sociedad, o el mismo Freud último al considerarla como vía de formación de la conciencia moral para una mayoría de individuos que no acceden a una moral autónoma madura-. Está bien valorar positivamente esa aportación de la herencia cultural de la religión -por otra parte, de aceptación ya muy discutible en sociedades posmodernas, poscristianas, de una secularidad agnóstica..., salvo en los sectores fundamentalistas o integristas que reactualizan la religión por su peor lado-, pero no deja de suponer un reduccionismo que no hace justicia a lo religioso. Las religiones no pueden tratar el "silencio de Dios" dejando de hablar de Dios, lo cual no es sino muestra de iglesias desubicadas en la sociedad secular, salvo para mantener sus privilegios en muchos casos (Estrada 2001: 214).

Si desde la religión se pretende mostrar razones de su creencia ("razones no racionalistas", diríamos, o "razones no expuestas en un discurso argumentativo", podríamos matizar), lo que corresponde a ello por parte de la filosofía es una tarea de evaluación crítica que no puede abandonar. No tiene la filosofía por qué desentenderse de evaluar la "racionalidad de propuestas religiosas" (Estrada 2005: 411), someter a crítica el decir teológico sobre Dios, aunque no pueda hablar directamente de Dios -o precisamente por eso- (Estrada 2003: 307). Es con tales propuestas como el filósofo Estrada sigue insistiendo por el lado de la filosofía en su quehacer a fondo respecto a la religión; eso sí, dando por supuesto que al defender la razonabilidad del cristianismo -en su caso- puede hablarse de una "razón teológica", lo cual no deja de ser asunto espinoso. Quizá para sortear objeciones, aunque al precio de expresiones que ponen de relieve la paradoja de la fe, Estrada (2010: 238) apunta salidas de razón práctica como esta: "El problema no es si Dios existe o no, sino si la creencia en Dios puede justificarse teórica y prácticamente porque contribuye a la justicia".

Nuestro filósofo, querido maestro, compañero y amigo, hace de su obra, con la lucha denodada que acomete a lo largo de toda ella, una "guía de perplejos". De vez en cuando aparece una pista en la que merece la pena seguir profundizando: cómo entender la "revelación", cuestión clave para sacarla de la condición de categoría falsamente puesta como premisa de desarrollos teológicos en los que la razonabilidad hace aguas, para abordarla desde criterios crítico-hermenéuticos en el sentido, recogido 
por Estrada, de lo que "el símbolo da que pensar". Es así como la filosofía se reafirma en su quehacer, a la vez que reconoce a la teología en su valor, sin caer en la maraña confusa de una "filosofía religiosa" contra la cual ya advertía Kant (Habermas 2005: 253). Estrada sabe que la tarea es inacabable. Y le acompañamos.

\section{Bibliografía}

\section{Adorno, Theodor W.}

1951 Minima moralia. Reflexiones desde la vida dañada. Madrid, Taurus, 1987.

Benjamin, Walter

1940 "Tesis de filosofía de la historia”, en Discursos interrumpidos, vol. I. Madrid, Taurus, Madrid, 1990.

Bloch, Ernst

1959 El principio esperanza (3 vols.). Madrid, Aguilar, 1980.

1968 El ateísmo en el cristianismo. La religión del éxodo y del Reino. Madrid, Taurus, 1983.

Estrada, Juan Antonio

1990 La teoría crítica de Max Horkheimer. Universidad de Granada, Granada.

1994 Dios en las tradiciones filosóficas, I. Aporías y problemas de la teología natural. Madrid, Trotta.

1996 Dios en las tradiciones filosóficas, II. De la muerte de Dios a la crisis del sujeto. Madrid, Trotta.

1997 La imposible teodicea. La crisis de la fe en Dios. Madrid, Trotta.

2001 Razones y sinrazones de la creencia religiosa. Madrid, Trotta.

2003 Imágenes de Dios. La filosofía ante el lenguaje religioso. Madrid, Trotta.

2004 Por una ética sin teología. Habermas como filósofo de la religión. Madrid, Trotta.

2005 La pregunta por Dios. Entre la metafísica, el nihilismo y la religión. Bilbao, Desclée de Brouwer.

2006 El cristianismo en una sociedad laica. Desclée de Brouwer, Bilbao.

2010 El sentido y el sinsentido de la vida. Preguntas a la filosofía y a la religión. Madrid, Trotta.

2015 ¿Qué decimos cuando hablamos de Dios? La fe en una cultura escéptica. Madrid, Trotta.

Feuerbach, Ludwig

1841 La esencia del cristianismo. Madrid, Trotta, 1998.

Gauchet, Marcel

1985 El desencantamiento del mundo. Madrid, Trotta, 2005.

Gómez Caffarena, José

1983 El teísmo moral de Kant. Madrid, Cristiandad.

Habermas, Jürgen

2001a Tiempo de transiciones. Madrid, Trotta.

2001b El futuro de la naturaleza humana. Barcelona, Paidós, 2002.

2005 Entre naturalismo y religión. Paidós, Barcelona, 2006.

2012 Mundo de la vida, política y religión. Madrid, Trotta, 2015.

Hegel, Georg W. F.

1807 Fenomenología del Espíritu. México D. F., 1966.

1848 Lecciones sobre la filosofía de la historia universal. Madrid, Alianza, 1986.

Horkheimer, Max

2000 Anhelo de justicia. Teoría crítica y religión. Madrid, Trotta.

Kant, Immanuel

1784 “Respuesta a la pregunta: ¿Qué es Ilustración?”, en En defensa de la Ilustración. Barcelona, Alba, 1999.

1793 La religión dentro de los límites de la mera razón. Madrid, Alianza, 1981. 
Kierkegaard, Søren

1843 Temor y temblor. Madrid, Tecnos, 1987.

1849 La enfermedad mortal. Madrid, Sarpe, 1984.

Lévinas, Emmanuel

1961 Totalidad e infinito. Ensayo sobre la exterioridad. Salamanca, Sígueme, 1995.

Pérez Tapias, José Antonio

1999 “El aguijón apocalíptico y la filosofía de la historia”, Diálogo Filosófico, n 43: 71-88.

2007 Del bienestar a la justicia. Aportaciones para una ciudadanía intercultural. Madrid, Trotta.

2019 Ser humano. Cuestión de dignidad en todas las culturas. Madrid, Trotta.

Ricoeur, Paul

1960 Finitud y culpabilidad. Madrid, Trotta, 2004.

Taylor, Charles

2007a La era secular I. Barcelona, Gedisa, 2014.

2007b La era secular II. Barcelona, Gedisa, 2015.

Voegelin, Eric

2000 Las religiones políticas. Madrid, Trotta, 2014. 